\title{
IDENTIFICATION OF GRP75 AS A NOVEL PRES1 BINDING PROTEIN USING A PROTEOMICS STRATEGY
}

\author{
Lunbiao Cui ${ }^{\$ *}$; Yiyue Ge*; Yuhua Qi; Zhiyang Shi; Yongjun Jiao; Xian Qi; Xiangjun Zhai; Hua Wang \\ Institute of Microbiology, Jiangsu Provincial Center for Diseases Prevention and Control, Nanjing 210009, China
}

Submitted: April 13, 2009; Returned to authors for corrections: May 19, 2009; Approved: May 27, 2009.

\begin{abstract}
The PreS1 region of the $\mathrm{L}$ protein is important in cell attachment and consequently in hepatitis B virus (HBV) infectivity. To identify novel PreS1 interacting protein, we performed Glutathione-S-transferase (GST) pull-down, two-dimensional gel electrophoresis (2-DE) and mass spectrometry assays. Glucoseregulated proteins (GRP) 78 and 75 were found to bind PreS1. The interactions between PreS1 and GRP75 were confirmed by a co-immunoprecipitation experiment. GRP78 and GRP75 may play important roles in mediating HBV virion entering into hepatocyte and regulating proper folding of the L protein due to their critical functions in protein folding and trafficking. The finding of novel PreS1 binding protein enriches our knowledge about molecular mechanism of HBV infection.
\end{abstract}

Key words: HBV, PreS1, Proteomics, GRP75

\section{INTRODUCTION}

The hepatitis B virus (HBV) is a worldwide cause of hepatic disease with variations in prevalence from region to region (13). China is one of the highest $\mathrm{HBV}$ prevalence areas. There are approximately 130 million HBV carriers in China. Current treatment for HBV infection has limited efficacy. The attachment to hepatocytes by HBV during infection has long been proposed to be a potential target for antiviral intervention. However, little is known about the molecular events mediating HBV attachment to hepatocytes. HBV PreS1 region, specifically, the aa 21-47 segment, is believed to play an essential role in mediating $\mathrm{HBV}$ attachment to the putative receptor on hepatocytes $(9,14)$. In the past two decades, Human immunoglobulin A $(\operatorname{Ig} \mathrm{A})$ receptor, a $31-\mathrm{kDa}$ protein, interleukin-6, a 44-kDa protein (HBV-BP), Homology to
SCCA1, a human squamous cell carcinoma antigen 1 (human serpin), $\quad \mathrm{p} 80$ (GRP78), a $35-\mathrm{kDa}$ protein homolous to Glycerinaldehyde-3-phoshate-dehydrgenase (GAPD), a serum glycoprotein of 50-kDa, and an asialoglycoproteinreceptor (ASGPR) have been proposed as PreS1 binding proteins (4), but none of these molecules has been identified as receptor in HBV infection.

With the rapid development in screening technology and bioinformatics, novel receptor or coreceptor candidates have been discovered recently. Deng found that lipoprotein lipase (LPL), a key enzyme in lipoprotein metabolism, might interact with PreS and HBV particles by using phage display library (3). Li et al. screened NACA as a novel PreS1 associated protein by using yeast two-hybrid system (10). Recently, proteomic techniques have been used as a new tool for studying protein-protein interaction. In this study, to identify

\footnotetext{
*Corresponding Author. Mailing address: Institute of Microbiology, Jiangsu Provincial Center for Diseases Prevention and Control, Nanjing 210009, China.; Fax: 86-25-83759371.; E-mail: lbcui@njmu.edu.cn

${ }^{\$}$ The first two authors are equal contributors to this study.
} 
novel PreS1 interacting protein, we performed Glutathione-Stransferase (GST) pull-down, high-resolution two-dimensional gel electrophoresis (2-DE) and mass spectrometry assays. GRP75 was identified as a novel PreS1 binding protein and its possible roles in virus infection are discussed. GRP78, a protein previously described to interact with preS1, was also identified in these assays.

\section{MATERIALS AND METHODS}

\section{GST fusion construct of PreS1}

The PreS1 fragment was amplified by PCR using HBV DNA as template extracted from serum of a chronically infected patient with $\mathrm{HBsAg}$, anti- $\mathrm{HBc}$, and $\mathrm{HBeAg}$ positive serology. PCR were performed using the following primers, $5^{\prime}$ AGCGGATCCATGGGAGGTTGGTCTTCCA-3' (forward) and 5'-ATATCTCGAGTTAGGCCTGAGGATGACTGT-3' (reverse). The PCR products were subsequently cloned as BamH I-Xho I fragments into pGEX-4T2 (Pharmacia) and recombinant vectors were introduced into the $E$. coli BL21 (DE3) (Invitrogen). The GST fusion proteins were induced as described previously and were purified from the bacterial cell lysates by affinity binding to glutathione sepharose beads (Pharmacia) as detailed elsewhere (11).

\section{GST pull-down assay}

HepG2 cells were lysed in binding buffer (50 mMTris$\mathrm{HCl}, \mathrm{pH} 8.0,150 \mathrm{mM} \mathrm{NaCl}, 5 \mathrm{mM}$ EDTA, 0.5\% NP-40, 1 $\mu \mathrm{g} / \mathrm{mL}$ leupeptin, $1 \mu \mathrm{g} / \mathrm{mL}$ aprotinin and $0.1 \mathrm{mM}$ PMSF.), and triplicate independent soluble protein fraction was incubated with GST and GST-PreS1 fusion proteins overnight at $4^{\circ} \mathrm{C}$. Then, co-precipitations were performed by addition of $80 \mu \mathrm{l}$ glutathione-sepharose 4B resin. After washing five times with $600 \mu \mathrm{l}$ of binding buffer, binding proteins were eluted with 200 $\mu \mathrm{l}$ of $10 \mathrm{mM}$ reduced glutathione in PBS. Eluted samples were precipitated with 4 volumes of cold acetone, centrifuged and the pellets were washed with $200 \mu \mathrm{l}$ of $20 \%$ (v/v) cold methanol. After centrifugation for $30 \mathrm{~min}$ at $12,000 \times \mathrm{g}$, pellets were air-dried and dissolved in rehydrating solution (8 M urea,
2\% CHAPS, 18mM dithiothreitol (DTT), $0.5 \%$ IPG buffer $\mathrm{pH}$ 3-10) for further 2-DE analysis.

\section{Two-dimensional gel electrophoresis (2-DE)}

2-DE was performed as described previously (2). Briefly, samples were subjected to isoelectric focusing (IEF) using IPG DryStrips with immobilized $\mathrm{pH}$ gradient, $\mathrm{pH}$ range 3-10, 17 $\mathrm{cm}$, linear (Bio-Rad). IEF was performed in an IPGphor (Amersham Biosciences) according to the following protocol: $30 \mathrm{~V} 6 \mathrm{~h}, 60 \mathrm{~V} 6 \mathrm{~h}, 500 \mathrm{~V} 1 \mathrm{~h}, 1000 \mathrm{~V} 1$ h, $8000 \mathrm{~V} \mathrm{3-4} \mathrm{h} \mathrm{to} 30$ $000 \mathrm{Vh}$. After IEF, strips were equilibrated in $50 \mathrm{mM}$ Tris$\mathrm{HCl}, \mathrm{pH} 8.8,6 \mathrm{M}$ urea, $2.0 \% \mathrm{SDS}, 30 \%$ glycerol with $1 \%$ DTT for $10 \mathrm{~min}$, and then for $10 \mathrm{~min}$ in the same buffer without DTT but with $4 \%$ iodoacetamide. Equilibrated strips were placed on top of $10 \%(\mathrm{w} / \mathrm{v})$ polyacrylamide gel to separate the proteins by molecular mass.

\section{Protein identification}

Protein spots were excised from the gels, destained, and subjected to in-gel digestion with trypsin (modified, sequence grade porcine; Promega), as described earlier (2). Tryptic peptides were dissolved in $2 \mu \mathrm{l}$ of $0.5 \%$ TFA containing the matrix (a-cyano-4-hydroxycinnamic acid) and analyzed by matrix-assisted laser desorption/ionization-time of flight-mass spectrometry (MALDI-TOF-MS) (Bruker Daltonics, Germany). Data were screened against the NCBInr databases using the MASCOT search program (www.matrixscience.com).

\section{Immunoprecipitation}

PreS1 gene was cloned into the BamH I and Hind restriction sites of pXJ40 (pXJ40-PreS1). Encoding domain of GRP75 gene was generated by using the forward primer (5'CTTAAGCTTGCCATGATAAGTGCCAGCCGAGCTG-3') and reverse primer $\left(5^{\prime}-\right.$

\section{CGCCTCGAGTATTACTGTTTTTCCTCCTTTTGATC-3’)}

and cloned into Hind and Xho I restriction sites of pXJ40 (pXJ40-GRP75). pXJ40-PreS1 and pXJ40-GRP75 were cotransfected into COS7 cells using Lipofectamine 2000 
(Invitrogen). $48 \mathrm{~h}$ after transfection, cells were washed with phosphate-buffered saline and lysed in $0.5 \mathrm{ml}$ lysis buffer (20 $\mathrm{mM}$ Tris- $\mathrm{HCl} \mathrm{pH}$ 8.0, $100 \mathrm{mM} \mathrm{NaCl}, 1 \mathrm{mM}$ EDTA, $0.5 \%$ NP40, $100 \mu \mathrm{mol} / \mathrm{L}$ PMSF, $1 \mu \mathrm{g} / \mathrm{mL}$ leupeptin, $1 \mu \mathrm{g} / \mathrm{mL}$ aprotinin). After brief sonication, the lysate was centrifugated at 15000 rpm for $15 \mathrm{~min}$ at $4^{\circ} \mathrm{C}$. The supernatant was incubated with mouse monoclonal anti-PreS1 antibody (Feipon Biotech Inc, China) overnight at $4^{\circ} \mathrm{C}$, then incubated with a slurry of protein-A-sepharose with rotation for $2 \mathrm{~h}$ at $4^{\circ} \mathrm{C}$. The beads were pelleted and washed five times with cell lysis buffer. Finally, proteins were solubilized in sodium dodecyl sulphatepolyacrylamide gel electrophoresis (SDS-PAGE) loading buffer by boiling.

\section{Western blot}

Samples were resolved in $8 \%$ or $17.5 \%$ polyacrylamide gel, and proteins were transferred to a nictrocellulose membrane. Immunoblotting was carried out using rabbit antiGRP75 antibody (Santa Cruz) or mouse anti-PreS1 antibody as indicated above and anti-rabbit or anti-mouse IgG-horseradish peroxidase (HRP) conjugates. After rinsing with PBS-T (phosphate-buffered saline [PBS] containing 0.1\% Tween 20), the blots were visualized by the enhanced chemiluminescence procedure as recommended by the supplier (Pierce).

\section{RESULTS}

\section{Preparation of GST-fusion construct of PreS1}

We sought to identify novel PreS1-binding proteins using a GST pull-down assay. To this end, an expression plasmid, pGEX4T2-PreS1 was generated carrying a full-length preS1 sequence. The GST-PreS1 fusion protein was expressed in $E$. coli BL21. SDS-PAGE analysis revealed that GST-PreS1 can be expressed and be co-purified with other proteins (Fig. 1A, lane 3). Similar to the previous study (11), Western blot analysis with anti-preS1 monoclonal antibody indicated a major band of a $39 \mathrm{~K}$ protein corresponding to the intact GSTPreS1, several bands of lower molecular weight proteins that most likely represent degradation products of the GST-preS1 fusion protein (Fig. 1B, lane 3).

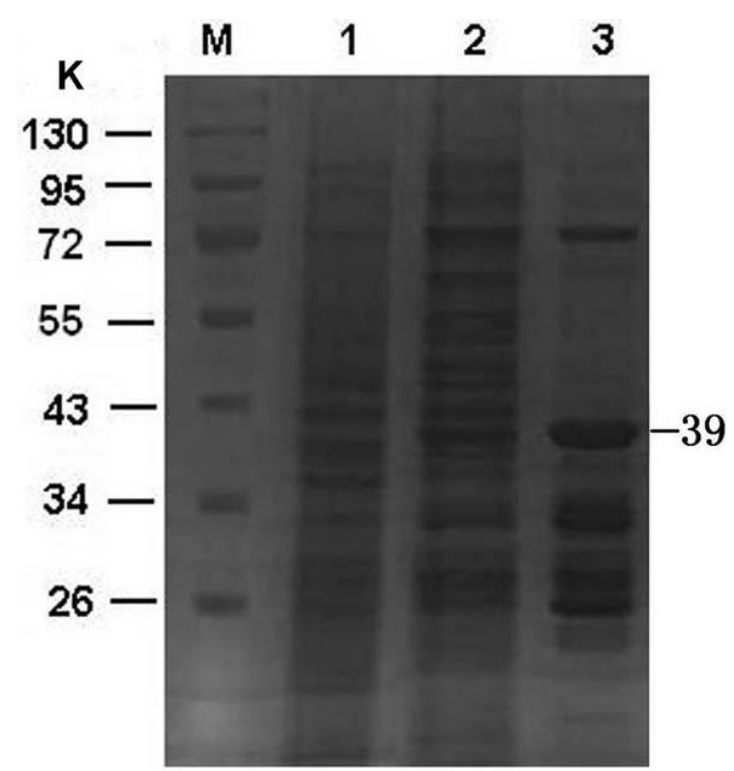

A

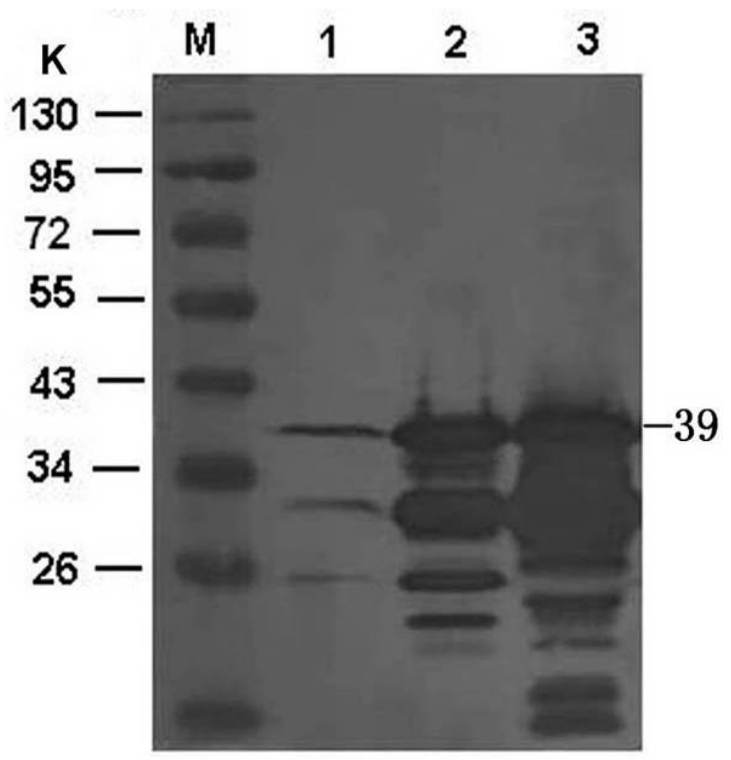

B

Figure 1. Expression and purification of the preS1. (A) $10 \%$ SDS-PAGE. B. Immunoblotting with anti-preS1 monoclonal antibody. Uninduced recombinant cell lysates, induced recombinant cell lysates, and GST-PreS1 protein purified using glutathione-agarose (lane 1, 2, and 3, respectively), molecular size markers (M) 


\section{2-DE analysis of proteins binding with PreS1}

To identify proteins associated with PreS1, the high resolving power of 2-DE was applied to the analysis. The GST and GST-PreS1 samples incubated with and without HepG2 cell lysate were separated using IPG strip in first dimension and $10 \%$ polyacrylamide gels in the second dimension (Fig.2). GST and GST-PreS1 samples incubated with binding buffer (Fig. 2A, B), GST sample incubated with HepG2 cell lysate (Fig. 2C) were set as control. Those protein spots appeared in the pull-down sample gel while not in the control gels were excised and further analyzed by MALDI-TOF-MS. Database searching showed that two proteins of HepG2 could bind with GST-PreS1, including GRP78 and GRP75 (Point 1, 2, Fig.

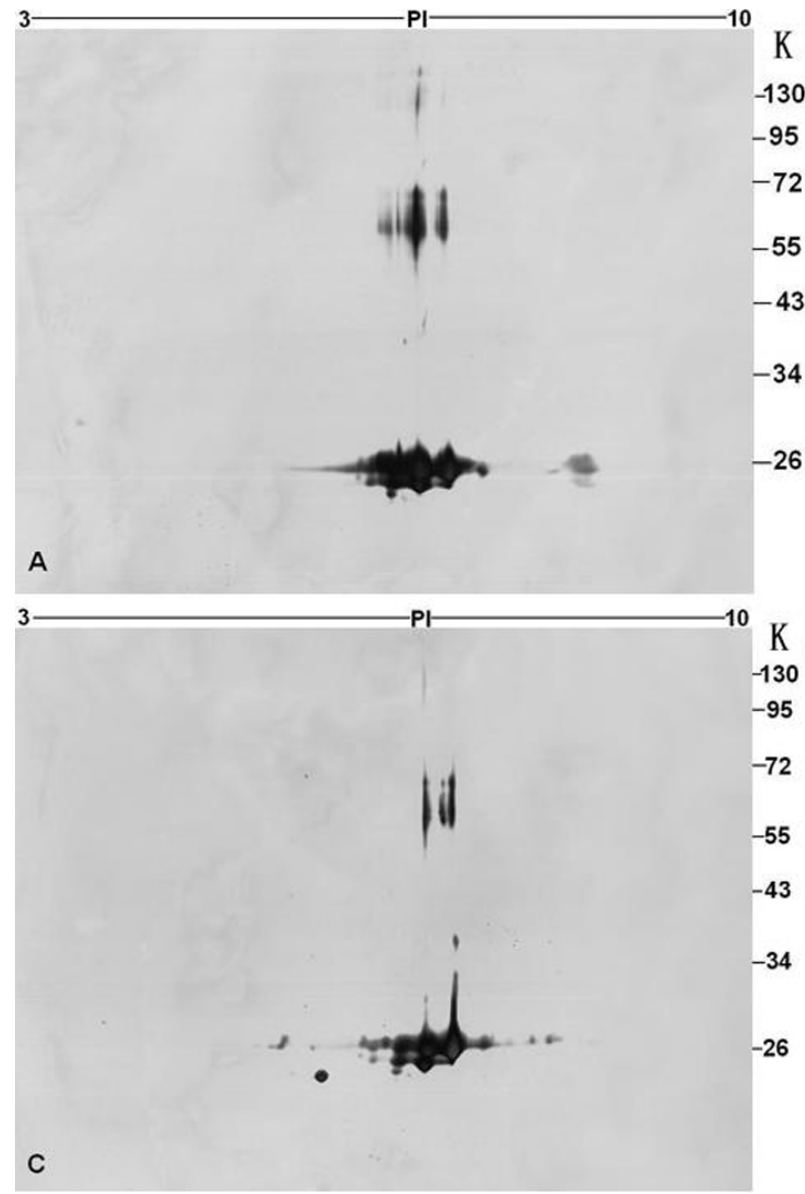

2D). Peptide masses and further data concerning protein identity are listed in Table 1.

\section{GRP75 associates with PreS1 in vivo}

It has been previously demonstrated that GRP78 bound specifically to the PreS1 in vitro and in vivo (1). In this study, we therefore opted to confirm the interaction between GRP75 and PreS1 in vivo. The coding sequence of PreS1 and GRP75 was cloned into pXJ40. COS-7 cells were co-transfected pXJ40-GRP75, pXJ40-PreS1, or empty vector. As shown in figure 3, anti-PreS1 antibody coimmunoprecipitated PreS1 and GRP75. It is thus possible that GRP75 is PreS1-associated protein.

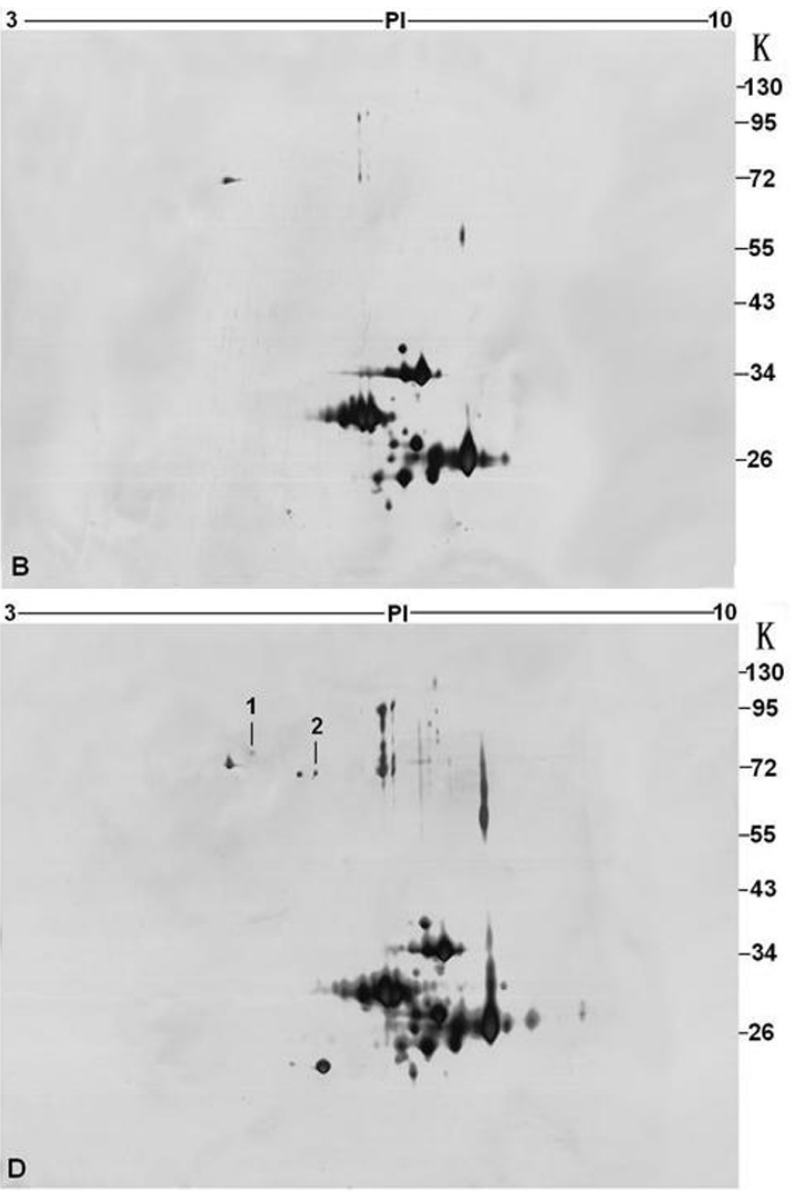

Figure 2. 2-DE analysis of GST-PreS1 binding protein. GST pull down using GST (A), GST-PreS1 (B) with binding buffer, GST (C) and GST-PreS1 (D) with HepG2 cell lysate. IEF on Immobiline DryStrips (pH range 3-10) followed by SDS-PAGE and silver staining. Protein spots 1 and 2 (D) were identified by MALDI-TOF-MS, one of which was GRP78 (point 1), another was GRP75 (point 2) 
Table 1. Protein identities and peptide masses

\begin{tabular}{|c|c|c|c|c|c|c|c|}
\hline $\begin{array}{l}\text { Protein } \\
\text { identified }\end{array}$ & $\begin{array}{c}\text { Actual } \\
\text { pI/Mw } \\
(\mathbf{k D a})\end{array}$ & $\begin{array}{c}\text { Calculated } \\
\text { pI/Mw } \\
\text { (kDa) } \\
\end{array}$ & $\begin{array}{c}\text { Sequence } \\
\text { coverage } \\
(\%)\end{array}$ & $\begin{array}{l}\text { Accessio } \\
\text { n no. }\end{array}$ & Identified peptide sequences & $\begin{array}{c}\text { Experimental } \\
\text { masses } \\
(\text { Da })\end{array}$ & $\begin{array}{c}\text { Calculated } \\
\text { masses } \\
\text { (Da) }\end{array}$ \\
\hline \multirow[t]{19}{*}{ GRP78 } & $5.4 / 76.9$ & $5.07 / 72.5$ & 38 & P11021 & NGRVEIIANDQGNR & 1554.8192 & 1554.7862 \\
\hline & & & & & ITPSYVAFTPEGERLIGDAAK & 2234.1613 & 2234.1582 \\
\hline & & & & & NQLTSNPENTVFDAKR & 1832.9256 & 1832.9016 \\
\hline & & & & & TWNDPSVQQDIK & 1429.7298 & 1429.6837 \\
\hline & & & & & TKPYIQVDIGGGQTK & 1603.8926 & 1603.8569 \\
\hline & & & & & TFAPEEISAMVLTK & 1535.8264 & 1535.7905 \\
\hline & & & & & KVTHAVVTVPAYFNDAQR & 2015.0681 & 2015.0588 \\
\hline & & & & & DAGTIAGLNVMR & 1216.6695 & 1216.6234 \\
\hline & & & & & IINEPTAAAIAYGLDKR & 1815.0120 & 1814.9890 \\
\hline & & & & & VMEHFIK & 902.4798 & 902.4684 \\
\hline & & & & & RALSSQHQAR & 1152.6457 & 1152.6112 \\
\hline & & & & & AKFEELNMDLFR & 1511.7843 & 1511.7442 \\
\hline & & & & & KSDIDEIVLVGGSTR & 1587.8874 & 1587.8467 \\
\hline & & & & & EFFNGKEPSR & 1209.6170 & 1209.5778 \\
\hline & & & & & VYEGERPLTK & 1190.6711 & 1190.6295 \\
\hline & & & & & DNHLLGTFDLTGIPPAPR & 1933.0238 & 1933.0057 \\
\hline & & & & & NKITITNDQNR & 1315.7127 & 1315.6844 \\
\hline & & & & & ITITNDQNRLTPEEIER & 2041.0551 & 2041.0440 \\
\hline & & & & & IDTRNELESYAYSLK & 1800.9108 & 1800.8893 \\
\hline \multirow[t]{21}{*}{ GRP75 } & $6.02 / 70.9$ & $5.87 / 73.9$ & 42 & P38646 & ISASRAAAAR & 972.5495 & 972.5464 \\
\hline & & & & & VLENAEGAR & 957.5069 & 957.4879 \\
\hline & & & & & TTPSVVAFTADGER & 1449.7553 & 1449.7099 \\
\hline & & & & & QAVTNPNNTFYATKR & 1723.8924 & 1723.8641 \\
\hline & & & & & RYDDPEVQK & 1148.5887 & 1148.5462 \\
\hline & & & & & ASNGDAWVEAHGK & 1340.6623 & 1340.6109 \\
\hline & & & & & NAVITVPAYFNDSQR & 1693.8750 & 1693.8423 \\
\hline & & & & & $\begin{array}{l}\text { DAGQISGLNVLRVINEPTAAA } \\
\text { LAYGLDK }\end{array}$ & 2868.3647 & 2868.5344 \\
\hline & & & & & STNGDTFLGGEDFDQALLR & 2054.9547 & 2054.9545 \\
\hline & & & & & ETGVDLTKDNMALQR & 1689.8679 & 1689.8355 \\
\hline & & & & & AQFEGIVTDLIRR & 1516.8740 & 1516.8361 \\
\hline & & & & & $\begin{array}{l}\text { AMQDAEVSKSDIGEVILVGG } \\
\text { MTR }\end{array}$ & 2405.1800 & 2405.1929 \\
\hline & & & & & SDIGEVILVGGMTR & 1445.8009 & 1445.7547 \\
\hline & & & & & VQQTVQDLFGRAPSK & 1672.9096 & 1672.8896 \\
\hline & & & & & SQVFSTAADGQTQVEIK & 1807.9123 & 1807.8952 \\
\hline & & & & & VCQGER & 747.3078 & 747.3333 \\
\hline & & & & & $\begin{array}{l}\text { EQQIVIQSSGGLSKDDIENMV } \\
\mathrm{K}\end{array}$ & 2417.1972 & 2417.2107 \\
\hline & & & & & YAEEDRR & 937.4381 & 937.4253 \\
\hline & & & & & ERVEAVNMAEGIIHDTETK & 2141.0647 & 2141.0422 \\
\hline & & & & & MRELLAR & 887.5015 & 887.5011 \\
\hline & & & & & KDSETGENIR & 1147.5712 & 1147.5469 \\
\hline
\end{tabular}




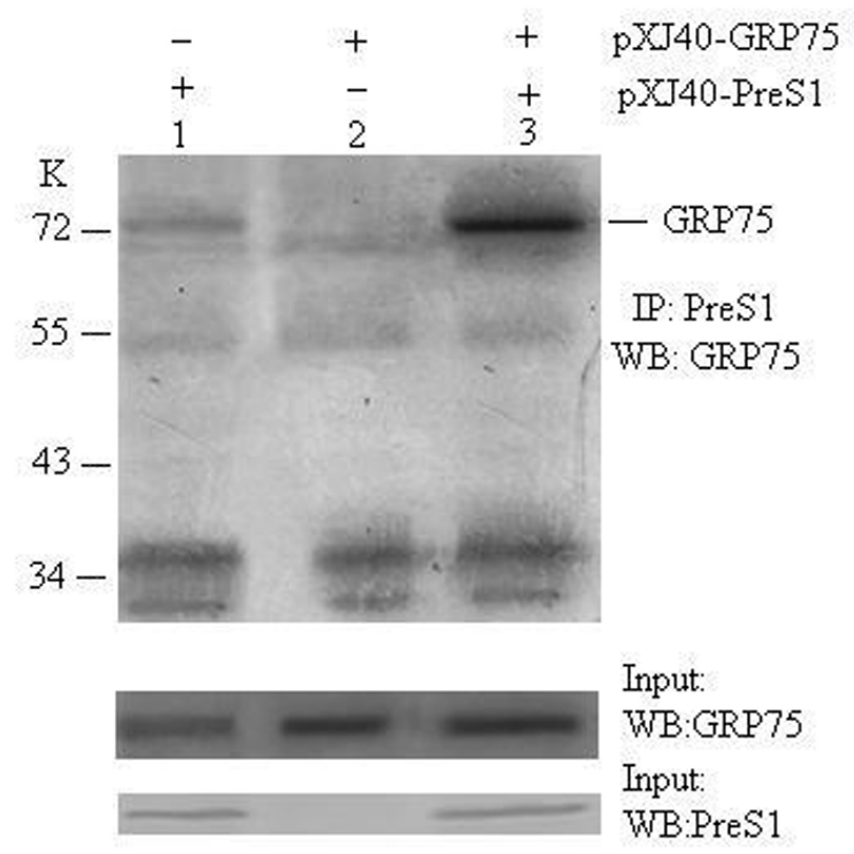

Figure 3. GRP75 binds to PreS1 in vivo. The COS7 cell lysates, co-transfected with pXJ40-PreS1 (lane 1) and pXJ40GRP75 (lane 2) either alone or both (lane 3), were immunoprecipitated with anti-PreS1 antibody. Lysates from the transfected cell and the immunoprecipitates were subjected to Western blot analysis using the anti-GRP75 antibody

\section{DISCUSSION}

GST pull down combining with proteomic techniques provided a powerful tool for studying protein-protein interaction in vitro. By using these methods, some novel protein-protein interaction partners have been clarified, such as PRS1 associated with p300 (6), HBx protein of HBV binding to mitochondrial HSP60 and HSP70 (18), PKC $\beta$ and CtBP interacted with BMPR-II (5).

Both GRP78 and GRP75 belong to HSP70 family (HSP70s) molecular chaperones which play critical roles in protein folding and trafficking (8). The major difference between GRP78 and GRP75 is the cellular localization. GRP78 almost localized in endoplasmic reticulum (ER) (8). While GRP75 mainly resided in mitochondria but also resided in ER and both of these protein are reported expressing in cell surface $(15,17)$.
HSP-70s are highly conserved and demonstrate a $60-78 \%$ base identity among eukaryotic cells. Biochemical studies have demonstrated that all HSP70s have N-terminal 44-kDa and 18$\mathrm{kDa}$ domain, C-terminal 10-kDa fragment. N-terminal 44-kDa domain is ATPase domain. $18-\mathrm{kDa}$ domain is peptide-binding domain. C-terminal 10-kDa fragment carries highly conserved EEVD terminal sequence (8). Therefore, it is likely that both GRP78 and GRP75 bound to PreS1 through N-terminal 18-kDa domain. GRP78 has been proved specifically bound to the PreS1 $(1,4)$. Using the receptor binding assay they determined that amino acid residues 12 to 20 and 82 to 90 are essential for the binding of pre-S1 to GRP78. Which site of PreS1 mediates its attachment to GRP75 should be established.

Functional meaning of PreS1 interacting with both proteins may be explained in two ways. First, GRP78 and GRP75 mediate HBV virion binding to hepatocyte and internalization. The other is regulating proper folding of the $\mathrm{L}$ protein. The former possibility comes from the fact GRP78 bound specifically to the pre-S1 of native HBV particles. The association of GRP75 with the IL-1 receptor type was detected and proposed to play an important role in receptor internalization (16). GRP75 was also isolated as a FGF-1 binding protein by FGF-1 affinity chromatography and was shown to aid in its intracellular trafficking (12). In view of the in vivo biological relevance of GRP78 and GRP75, combined with the cell surface location, we postulate that one of role of GRP78 and GRP75 may be act as an adjunctive carrier in bridging HBV virion entry into the cell during viral infection. L protein are synthesized at ER. It has also been suggested that one of function of HSP-70s is to prevent transport of incompletely assembled, misfolded, or aggregated proteins from the ER $(1,7,8)$. By analogy, we may therefore infer GRP78 and GRP75 may interact with the incompletely assembled L protein particles and retains them in the lumen of ER to prevent their secretion. Whether GRP78 and GRP75 involved in HBV morphogenesis by regulating proper folding of the L protein warrants further study.

In summary, we identified GRP75 as a novel PreS1 interacting protein besides GRP78, a protein previously 
described to interact with preS1, using GST pull down combining with proteomic techniques. We postulate that GRP78 and GRP75 may play important roles in mediating HBV virion entering into hepatocyte and regulating proper folding of the $\mathrm{L}$ protein due to their critical functions in protein folding and trafficking.

\section{ACKNOWLEDGEMENTS}

This study was supported by the Natural Science Foundation of Jiangsu Province (No. BK2007608) and Jiangsu Provincial Grant (No.BE2008683).

\section{REFERENCES}

1. Cho, D.Y.; Yang, G..H.; Ryu, C.J.; Hong, H.J. (2003). Molecular chaperone GRP78/BiP interacts with the large surface protein of hepatitis B virus in vitro and in vivo. J. Virol., 77, 2784-2788.

2. Cui, L.; Wang, Y.; Shi, Y.; Zhang, Z.; Xia, Y.; Sun, H.; Wang, S.; Chen, J.; Zhang, W.; Lu, Q.; Song, L.; Wei, Q.; Zhang, R.; Wang, X. (2007). Overexpression of annexin a1 induced by terephthalic acid-calculi in rat bladder cancer. Proteomics., 7, 4192-4202.

3. Deng, Q.; Zhuang, M.; Kong, Y.Y.; Xie, Y.H.; Wang, Y. (2005). Screening for PreS specific binding ligands with a phage displayed peptides library. World. J. Gastroenterol., 11, 4018-4023.

4. Glebe, D.; Urban, S.; (2007). Viral and cellular determinants involved in hepadnaviral entry. World. J. Gastroenterol., 13, 22-38.

5. Hassel, S.; Eichner, A.; Yakymovych, M.; Hellman, U.; Knaus, P.; Souchelnytskyi, S. (2004). Proteins associated with type II bone morphogenetic protein receptor (BMPR-II) and identified by twodimensional gel electrophoresis and mass spectrometry. Proteomics., 4, 1346-1358.

6. Kaida, A.; Ariumi, Y.; Baba, K.; Matsubae, M.; Takao, T.; Shimotohno, K. (2005). Identification of a novel p300-specific-associating protein,
PRS1 (phosphoribosylpyrophosphate synthetase subunit 1). Biochem. J., 391, 239-247.

7. Kaul, S.C.; Deocaris, C.C.; Wadhwa, R. (2007). Three faces of mortalin: a housekeeper, guardian and killer. Exp. Gerontol., 42, 263-274.

8. Kiang, J.G.; Tsokos, G.C. (1998). Heat shock protein 70 kDa: molecular biology, biochemistry, and physiology. Pharmacol. Ther., 80,183-120.

9. Le Seyec, J.; Chouteau, P.; Cannie, I.; Guguen-Guillouzo, C.; Gripon, P. (1999). Infection process of the hepatitis B virus depends on the presence of a defined sequence in the pre-S1 domain. J. Virol., 73, 2052-2057.

10. Li, D.; Wang, X.Z.; Chen, Z.X.; Huang, Y.H. (2003). Screening the hepatitis B virus PreS1 associated protein by the yeast two-hybrid system. Chin. J. Hepatol (Chin)., 11, 334-337.

11. Maeng, C.Y.; Oh, M.S.; Park, I.H.; Hong, H.J. (2001). Purification and structural analysis of the hepatitis B virus PreS1 expressed from escherichia coli. Biochem. Biophys. Res. Commun., 282, 787-792.

12. Mizukoshi, E.; Suzuki, M.; Loupatov, A.; Uruno, T.; Hayashi, H.; Misono, T.; Kaul, S.C.; Wadhwa, R.; Imamura, T. (1999). Fibroblast growth factor-1 interacts with the glucose-regulated protein GRP75/mortalin. Biochem. J., 343, 461-466.

13. Paiva1, E.M.M.; Tiplle, A.F.V.; Silva, E.P.; Cardoso, D.D.P. (2008). Serological markers and risk factors related to hepatitis B virus in dentists in the Central West region of Brazil. Braz. J. Microbiol., 39, 251256.

14. Pontisso, P.; Alberti, A. (1991). The role of preS1 in the interaction of hepatitis B virus with human hepatocytes. Hepatology., 14, 405-406.

15. Ran, Q.; Wadhwa, R.; Kawai, R.; Kaul, S.C.; Sifers, R.N.; Bick, R.J.; Smith, J.R.; Pereira-Smith, O.M. (2000). Extramitochondrial localization of mortalin / mthsp70 / PBP74 / GRP75. Biochem. Biophys. Res. Commun., 275, 174-179.

16. Sacht, G..; Brigelius-Flohé, R.; Kiess, M.; Sztajer, H.; Flohé, L. (1999). ATP-sensitive association of mortalin with the IL-1 receptor type I. Biofactors., 9, 49-60.

17. Singh, B.; Soltys, B.J.; Wu, Z.C.; Patel, H.V.; Freeman, K.B.; Gupta, R.S. (1997). Cloning and some novel characteristics of mitochondrial Hsp70 from Chinese hamster cells. Exp. Cell.Res., 234, 205-216.

18. Zhang, S.M.; Sun, D.C.; Lou, S.; Bo, X.C.; Lu, Z.; Qian, X.H.; Wang, S.Q. (2005). HBx protein of hepatitis B virus (HBV) can form complex with mitochondrial HSP60 and HSP70. Arch. Virol., 150, 1579-1590. 